Research

\title{
Early effect of a single intravenous injection of ethanol on hepatic sinusoidal endothelial fenestrae in rabbits
} Frank Jacobs ${ }^{1}$, Eddie Wisse ${ }^{2,3}$ and Bart De Geest*1

\begin{abstract}
Address: ${ }^{1}$ Center for Molecular and Vascular Biology, Department of Molecular and Cellular Medicine, University of Leuven, Herestraat 49 , Leuven, 3000, Belgium, 2EM Unit Pathology Department, University of Maastricht, Universiteitssingel 50, Maastricht, 6229-ER, the Netherlands and ${ }^{3}$ Department of Internal Medicine, University of Maastricht, Universiteitssingel 50, Maastricht, 6229-ER, the Netherlands

Email: Frank Jacobs - frank.jacobs@med.kuleuven.be; Eddie Wisse - eddie@wisse.be; Bart De Geest* - bart.degeest@med.kuleuven.be

* Corresponding author
\end{abstract}

Published: 13 July 2009

Comparative Hepatology 2009, 8:4 doi:10.1 186/1476-5926-8-4
Received: 25 March 2009

Accepted: 13 July 2009

This article is available from: http://www.comparative-hepatology.com/content/8/1/4

(C) 2009 Jacobs et al; licensee BioMed Central Ltd.

This is an Open Access article distributed under the terms of the Creative Commons Attribution License (http://creativecommons.org/licenses/by/2.0), which permits unrestricted use, distribution, and reproduction in any medium, provided the original work is properly cited.

\begin{abstract}
Background: It has been postulated that ethanol affects hepatic sinusoidal and perisinusoidal cells. In the current experimental study, we investigated the early effect of a single intravenous dose of ethanol on the diameter of liver sinusoidal endothelial fenestrae in New Zealand White rabbits. The diameter of fenestrae in these rabbits is similar to the diameter found in humans with healthy livers. The effect of ethanol on the size of fenestrae was studied using transmission electron microscopy, because plastic embedding provides true measures for the diameter of fenestrae.
\end{abstract}

Results: After intravenous administration of a single dose of $0.75 \mathrm{~g} / \mathrm{kg}$, ethanol concentration peaked at $1.1 \pm 0.10 \mathrm{~g} / \mathrm{l}$ at ten minutes after injection. Compared to control rabbits $(103 \pm \mathrm{I} . \mathrm{I} \mathrm{nm}$; $n=8)$, the average diameter of fenestrae in ethanol-injected rabbits determined at 10 minutes after injection was significantly $(p<0.01)$ smaller $(96 \pm 2.2 \mathrm{~nm} ; n=5)$. Detailed analysis of distribution histograms of the diameters of fenestrae showed that the effect of ethanol was highly homogeneous.

Conclusion: A decrease of the diameter of fenestrae 10 minutes after ethanol administration is likely the earliest morphological alteration induced by ethanol in the liver and underscores the potential role of liver sinusoidal endothelial cells in alcoholic liver injury.

\section{Background}

It has been postulated that ethanol primarily targets hepatic sinusoidal and perisinusoidal cells [1]. In experimental models and in human studies, plasma hyaluronic acid levels are elevated in alcoholic liver injury, which may reflect a diminished hepatic clearance by liver sinusoidal endothelial cells [2-4]. Chronic ethanol exposure leads to defenestration in liver sinusoidal endothelial cells which is paralleled by the deposition of a basal lamina [5]. Subsequently, capillarization of hepatic sinusoids further impairs microcirculatory exchange of nutrients and the clearance of waste products, enhances tissue fibrosis, and will affect the hepatic parenchyma and its metabolism. Whereas this sequence of events has been corroborated by several studies, it is not well established to which extent a single administration of ethanol affects liver sinusoidal endothelial cells. Previous studies have shown that ethanol slightly $(6 \%)$ increases the diameter of fenestrae in liver sinusoidal endothelial cells in vitro $[6,7]$. In contrast, scanning electron microscopy studies in vivo showed significant decreases of the diameter of sinusoidal endothelial fenestrae [8], suggesting that the transport of plasma substances from sinusoids to parenchymal liver cells may already be impaired by acute ethanol intake. 
Because scanning electron microscopy is applied on dried and thus shrunken specimens, lege artis determination of the diameter of fenestrae requires transmission electron microscopy of plastic-embedded specimens. Quantification of the diameters in these sections is performed on fenestrae that become visible as holes when the sinusoidal wall is cut tangentially. The goal of the current investigation was to establish unambiguously whether a single intravenous injection of ethanol administration has an effect on the diameter of fenestrae in vivo. We have recently shown that the diameter of fenestrae in human healthy livers, fixed by injecting glutaraldehyde into fresh wedge biopsies, is similar compared to fenestrae in the livers of New Zealand White rabbits [9] and is significantly smaller than in mice [10] or rats [11]. Therefore, diameters were determined using transmission electron microscopy ten minutes after injection of ethanol or $0.9 \% \mathrm{NaCl}$ in New Zealand White rabbits.

\section{Results}

A dose of $0.75 \mathrm{~g} / \mathrm{kg}$ ethanol was administered intravenously via a marginal ear vein to male New Zealand White rabbits. The ethanol concentration in plasma is shown in Figure 1. Ethanol concentration peaked at $1.1 \pm 0.10 \mathrm{~g} / \mathrm{l}$ ( $\mathrm{n}$ $=5)$ at 10 minutes and was $0.35 \pm 0.041 \mathrm{~g} / \mathrm{l}(\mathrm{n}=5)$ at 2 hours after injection. Ethanol was below detection limit $(0.06 \mathrm{~g} / \mathrm{l})$ at 4 hours after injection. The time-point corresponding to the peak ethanol concentration (10 minutes

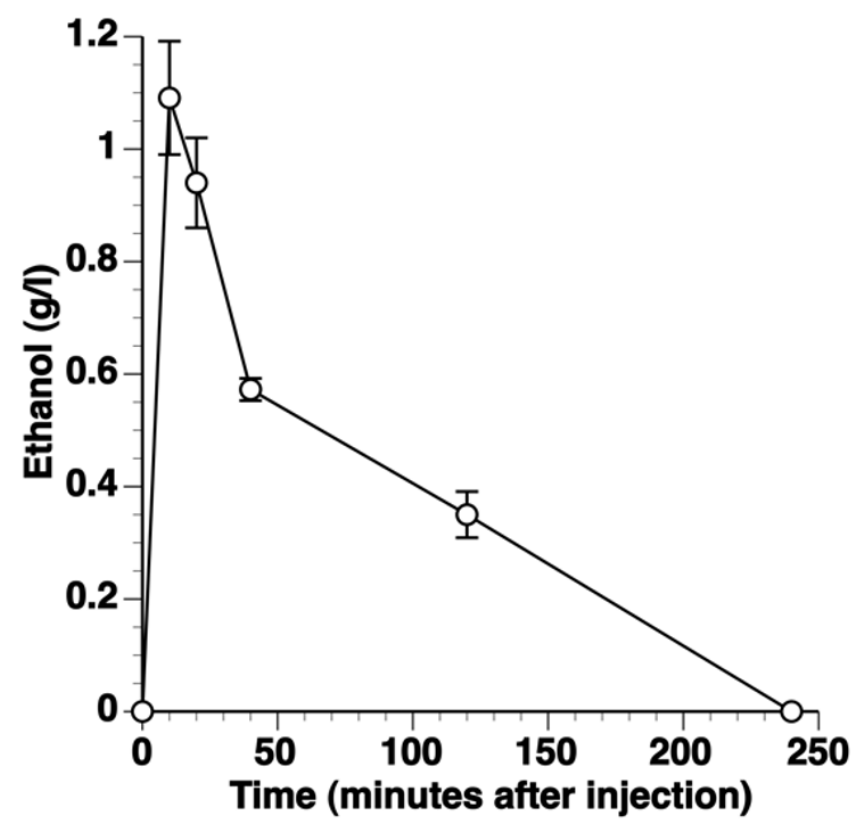

Figure I

Plasma ethanol concentrations in New Zealand

White rabbits. Ethanol concentration $(\mathrm{g} / \mathrm{l})$ in New Zealand White rabbits injected with $0.75 \mathrm{~g} / \mathrm{kg}$ ethanol. Data are expressed as means $\pm \operatorname{SEM}(n=5)$. after injection) was chosen to determine the diameter of fenestrae by transmission electron microscopy.

A representative transmission electron micrograph used to measure the diameter of fenestrae in male New Zealand White rabbits is shown in Figure 2. The average number of measurements per liver was $640 \pm 98(\mathrm{n}=8)$ and $690 \pm 67$ $(\mathrm{n}=5)$ in $0.9 \% \mathrm{NaCl}$ and ethanol-injected rabbits, respectively. The frequency distribution histogram of diameters of liver sinusoidal fenestrae determined by transmission electron microscopy 10 minutes after injection of $0.9 \%$ $\mathrm{NaCl}$ or ethanol is provided in Figure 3. Compared to control rabbits $(103 \pm 1.1 \mathrm{~nm})$, the average diameter of fenestrae in ethanol-injected rabbits was significantly smaller $(96 \pm 2.2 \mathrm{~nm} ; \mathrm{p}<0.01)$. The effect of ethanol on the diameter of fenestrae was homogeneous (Figure 3 ) as evidenced by significant reductions of the percentile 10 $(72 \pm 1.7 \mathrm{~nm}$ versus $79 \pm 1.1 \mathrm{~nm} ; \mathrm{p}<0.01)$, percentile 25 $(82 \pm 1.7 \mathrm{~nm}$ versus $89 \pm 1.3 \mathrm{~nm} ; \mathrm{p}<0.05)$, median $(94 \pm$ $1.8 \mathrm{~nm}$ versus $100 \pm 1.3 \mathrm{~nm} ; \mathrm{p}<0.05)$, percentile $75(107$ $\pm 2.3 \mathrm{~nm}$ versus $113 \pm 1.4 \mathrm{~nm} ; \mathrm{p}<0.05)$ and percentile 90 values $(122 \pm 3.2 \mathrm{~nm}$ versus $130 \pm 1.4 ; \mathrm{p}<0.05 \mathrm{~nm})$ in ethanol-treated rabbits compared to control rabbits.

\section{Discussion}

The current study, using lege artis transmission electron microscopy measurements, shows that ethanol at toxico-

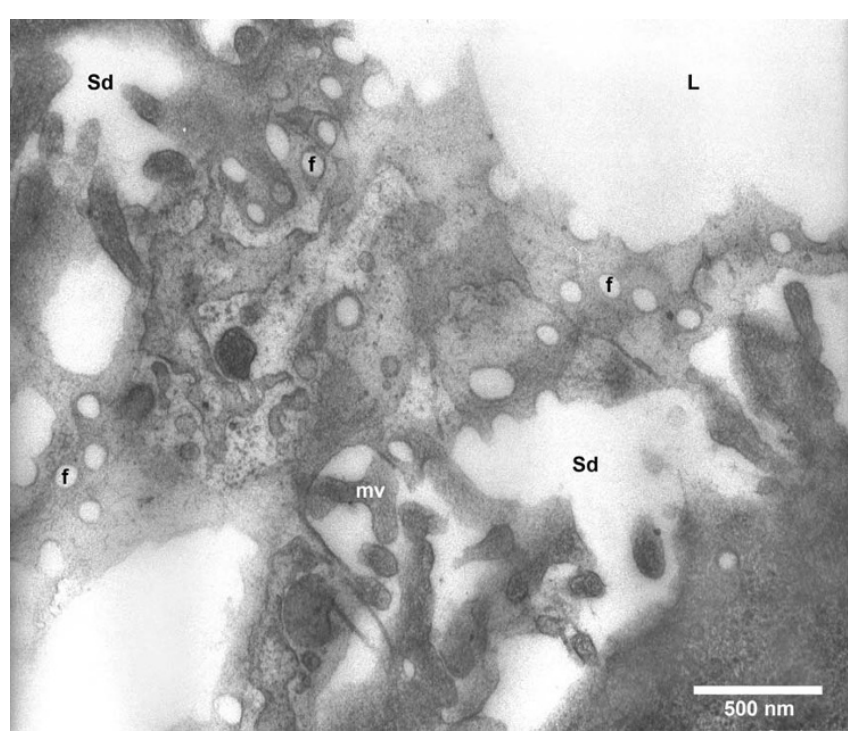

Figure 2

Transmission electron micrograph of liver sinusoidal endothelial fenestrae in New Zealand White rabbits.

The endothelial lining is cut tangentially and shows the occurrence of fenestrae ( $f$ ) mostly in groups, called sieve plates. To the left and the right hand side of the picture, we find the space of Disse (Sd) with sparse microvilli (mv) protruding from parenchymal cells. The right top corner of the picture shows the lumen $(\mathrm{L})$ of the sinusoid. The right bottom part of the picture shows the cytoplasm of a parenchymal cell. 


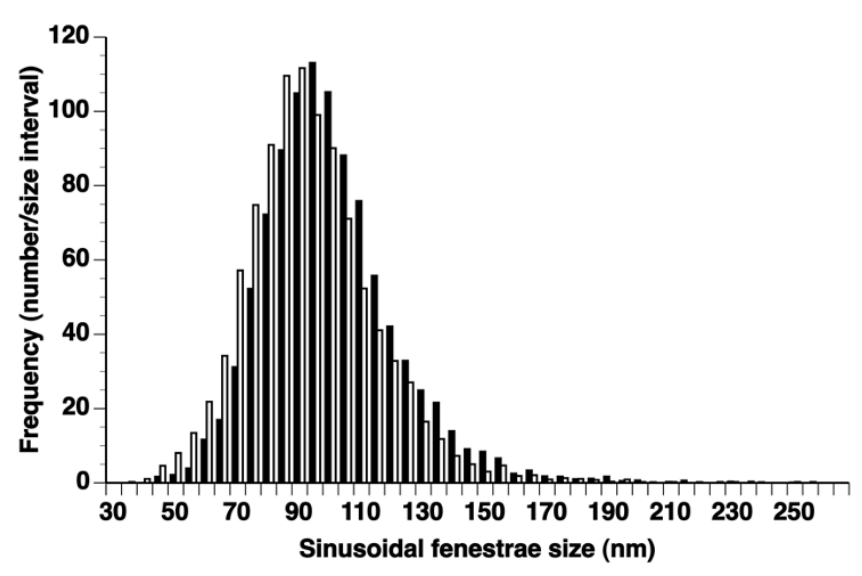

Figure 3

Frequency distribution histograms of the diameter of liver sinusoidal endothelial fenestrae in New Zealand White rabbits. Comparison of the frequency distribution histograms of the size of sinusoidal fenestrae in New Zealand White control rabbits (black bars; $n=8$ ) and New Zealand White rabbits injected with $0.75 \mathrm{~g} / \mathrm{kg}$ ethanol 10 minutes before perfusion fixation (white bars; $n=5$ ). Each bar corresponds to a $5 \mathrm{~nm}$ interval.

logically relevant levels significantly decreases the diameter of fenestrae in New Zealand White rabbits. Since this effect was observed ten minutes after ethanol injection, this study is in line with the view that the liver sinusoidal endothelial cells are the first hepatic cells that undergo morphological changes in alcoholemia [1].

Both endothelin-1 and NO may play a role in the effect of ethanol on the diameter of fenestrae. Previously, it has been demonstrated that ethanol induces hepatic vasoconstriction in isolated perfused rat liver and that endothelin1 antibodies significantly inhibit this ethanol-induced hepatic vasoconstriction [12]. Since endothelin-1 has been shown to induce contraction of hepatic sinusoidal endothelial fenestrae [13], endothelin-1 may mediate the decrease of the diameter of fenestrae after ethanol injection. Although hepatic vasoconstriction in isolated perfused rat liver persists during ethanol exposure, portal pressure gradually decreases [12]. This attenuation of ethanol induced vasoconstriction is mediated by NO[12]. Similarly, NO may oppose the contraction of hepatic sinusoidal endothelial fenestrae by endothelin-1: it induces a decrease in the cytosolic free calcium concentration leading to the dissociation of calcium and calmodulin from the myosin light chain kinase. Under these conditions, myosin light chain phosphatase dephosphorylates the myosin light chain and causes relaxation of fenestrae [14]. NO bioavailability in the sinusoid in the presence of ethanol will depend on two opposing factors. On the one hand, ethanol increases both endothelial NOS
(eNOS) expression and NO production [15]. On the other hand, ethanol has also been shown to induce a release of superoxide anions into the hepatic sinusoid [16,17], reducing NO bioavailability. The source of superoxide may be the liver sinusoidal endothelial cells [16] themselves as well as Kupffer cells [17]. Differences in endothelin-1 production and NO bioavailability between the in vitro setting and in vivo experiments may explain the discrepant results between different studies [6-8]. Whereas previous in vitro studies [6,7] have shown that ethanol slightly increases the diameter of fenestrae in liver sinusoidal endothelial cells, an in vivo scanning electron microscopy study in rats showed significant decreases in the diameter of sinusoidal endothelial fenestrae [8], similar as in the current study.

Previously, it has been shown that acute ethanol administration in Balb/c mice increased hyaluronic acid levels, a functional marker for sinusoidal endothelial liver cells, at 3 hours and 6 hours, whereas alanine aminotransferase levels, a marker of hepatocyte damage, were unchanged [4]. In the current study, a decrease of the diameter of fenestrae was observed as early as 10 minutes after injection. This may be the first effect of ethanol on liver sinusoidal endothelial cells and the earliest morphological alteration induced by ethanol in the liver. The smaller diameter of sinusoidal endothelial fenestrae following acute ethanol intake may induce a decrease of microcirculatory exchanges between the sinusoidal lumen and the space of Disse. This may contribute to protection of parenchymal liver cells from the toxic effects of ethanol.

\section{Conclusion}

The current study, showing a reduced diameter of fenestrae within 10 minutes following a single intravenous ethanol administration, underscores the potential role of liver sinusoidal endothelial cells in alcoholic liver injury. The reduction in the diameter of sinusoidal fenestrae may reduce the exchange between the sinusoidal lumen and the space of Disse and may therefore contribute to protecting parenchymal liver cells from the toxic effects of ethanol.

\section{Methods}

\section{Animal experiments}

All experimental procedures in animals were performed in accordance with protocols approved by the Institutional Animal Care and Research Advisory Committee. The investigation conforms with the Guide for the Care and Use of Laboratory Animals published by the US National Institutes of Health (NIH Publication No. 85-23, revised 1996). New Zealand White rabbits were obtained from the University of Gent (Merelbeke, Belgium). Experiments were performed at the age of 4 months. 


\section{Study design}

A dose of $0.75 \mathrm{~g} / \mathrm{kg}$ ethanol was administered intravenously via a marginal ear vein to male New Zealand White rabbits $(\mathrm{n}=5)$ at the age of 3 months and blood sampling was performed at 0 minutes, 10 minutes, 30 minutes, 2 hours and 4 hours. In separate experiments, male New Zealand White rabbits were intravenously injected with $0.9 \% \mathrm{NaCl}(\mathrm{n}=8)$ or $0.75 \mathrm{~g} / \mathrm{kg}$ ethanol $(\mathrm{n}=5) 10$ minutes before perfusion fixation of the rabbit liver. The average weight of rabbits in these experiments was $2.9 \pm 0.25 \mathrm{~kg}$ $(\mathrm{n}=18)$ and was not significantly different between different groups.

\section{Blood sampling}

Blood was obtained from the central ear artery and anticoagulated with $1 / 10$ volume of trisodium citrate. Samples were taken after an overnight fast.

\section{Determination of ethanol concentrations in plasma}

Plasma ethanol concentrations were measured using the alcohol dehydrogenase assay-based ethyl alcohol Flex ${ }^{\mathrm{TM}}$ reagent cartridge (Dade Behring Inc., Newark, DE, U.S.A.) on a Dade Behring Dimension ${ }^{\circledR}$ automated clinical chemistry analyzer (Dade Behring Inc.).

\section{Quantification of the size of sinusoidal fenestrae by transmission electron microscopy}

Perfusion of the rabbit liver with a fixative solution was performed essentially as described before [18-20]. After isoflurane anesthesia and exposure of the liver by laparotomy, the hepatic artery and common bile duct were clamped and two ligatures were placed around the portal vein. A sharpened 14-gauge pipette was introduced in the portal vein and fixed by tightening the two ligatures. Perfusion fixation was performed at a pressure of $15 \mathrm{~cm} \mathrm{H}_{2} \mathrm{O}$ with 250 to $300 \mathrm{ml}$ of $1.5 \%$ glutaraldehyde fixative buffered in $0.067 \mathrm{M}$ cacodylate at $\mathrm{pH}$ 7.4. The inferior caval vein was transsected at the start of the perfusion. The perfusion was continued until the colour of the liver changed from dark reddish brown to yellow brown and the consistency from soft to stiff (equivalent to the stiffness of a hard boiled egg). The liver was removed and thin slices were cut with a razor blade into $30-401 \mathrm{~mm}^{3}$ blocks from a left liver lobe as well as from a right liver lobe. These blocks were washed in cacodylate buffer and transferred to a $1 \% \mathrm{OsO}_{4}$ fixative solution buffered with phosphate buffered saline $0.1 \mathrm{M} \mathrm{pH} 7.4$ for subsequent immersion fixation during 1 hour at $4^{\circ} \mathrm{C}$. After washing in phosphate buffered saline 0.1 M pH 7.4, dehydration was carried out rapidly in graded ethanol series $\left(70^{\circ}-100^{\circ}\right)$, followed by embedding in Epon. Sections with a thickness of $2 \mu \mathrm{m}$ were cut for light microscopy to check the quality of the fixation and embedding. Subsequently, ultrathin sections for transmission electron microscopy were cut with an ultramicrotome with diamond knife. These sections have a typical thickness of $60 \mathrm{~nm}$. Five to ten ultrathin sections with a length and width of 500 to $1000 \mu \mathrm{m}$ were mounted on 75 mesh copper grids ( $3 \mathrm{~mm}$ diameter) with a carboncoated Formvar film, and subsequently contrasted with uranyl acetate and lead citrate. As a size reference, a calibration grid with a spacing of $463 \mathrm{~nm}$ was photographed at a magnification of $8400 \times$ at the beginning of each session. The specimens were examined at the University of Maastricht (EM unit, Pathology) in a Philips CM 100 (F.E.I., Eindhoven, The Netherlands) at $80 \mathrm{kV}$. The size of fenestrae was measured as the largest diameter in sections that cut the endothelial wall tangentially and show the fenestrae as complete holes. Measurements were performed manually on a monitor using Image software (Wayne Rasband, National Institutes of Health, USA, http://rsbweb.nih.gov/ij/). For each rabbit, ultrathin sections originating from two independent $1 \mathrm{~mm}^{3}$ blocks (corresponding to the right and left liver lobe) were analysed.

\section{Statistical analysis}

All data are expressed as means \pm standard error of the means (SEM). The diameters of fenestrae in saline and ethanol-injected rabbits were compared by a Student's ttest using Instat3 (GraphPad Software). Gaussian distribution of the data was tested using the method of Kolmogorov and Smirnov. The homogeneity of variances between groups was checked with Levene's test for equality of variances. A two-sided p-value of less than 0.05 was considered statistically significant.

\section{Competing interests}

The authors declare that they have no competing interests.

\section{Authors' contributions}

FJ and EW acquired, analysed and interpreted data. EW and BDG conceived and designed the research. All authors made critical revision of the manuscript for important intellectual content.

\section{Acknowledgements}

This work was supported by grant G.0322.06 of the Fonds voor Wetenschappelijk Onderzoek-Vlaanderen. The Center for Molecular and Vascular Biology is supported by the Excellentiefinanciering KU Leuven (EF/05/0I3). Frank Jacobs is a Research Assistant of the Instituut voor de Aanmoediging van Innovatie door Wetenschap en Technologie in Vlaanderen.

\section{References}

I. Deaciuc IV, Spitzer J): Hepatic sinusoidal endothelial cell in alcoholemia and endotoxemia. Alcohol Clin Exp Res 1996, 20(4):607-6|4.

2. Engstrom-Laurent A, Loof L, Nyberg A, Schroder T: Increased serum levels of hyaluronate in liver disease. Hepatology 1985 , 5(4):638-642.

3. Gibson PR, Fraser JR, Brown TJ, Finch CF, Jones PA, Colman JC, Dudley FJ: Hemodynamic and liver function predictors of serum hyaluronan in alcoholic liver disease. Hepatology 1992, I 5(6): | 054-1059. 
4. Sarphie G, D'Souza NB, Van Thiel DH, Hill D, McClain CJ, Deaciuc IV: Dose- and time-dependent effects of ethanol on functional and structural aspects of the liver sinusoid in the mouse. Alcohol Clin Exp Res 1997, 2 I (6): I I 28- I I 36.

5. Wang BY, Ju XH, Fu BY, Zhang J, Cao YX: Effects of ethanol on liver sinusoidal endothelial cells-fenestrae of rats. Hepatobiliary Pancreat Dis Int 2005, 4(3):422-426.

6. Braet F, De Zanger R, Baekeland M, Crabbe E, Smissen P Van Der, Wisse E: Structure and dynamics of the fenestrae-associated cytoskeleton of rat liver sinusoidal endothelial cells. Hepatology 1995, 21(1): 180-189.

7. Braet F, Kalle WH, De Zanger RB, De Grooth BG, Raap AK, Tanke $\mathrm{HJ}$, Wisse $\mathrm{E}$ : Comparative atomic force and scanning electron microscopy: an investigation on fenestrated endothelial cells in vitro. J Microsc 1996, I8I(Pt I): I0-I7.

8. Takashimizu S, Watanabe N, Nishizaki Y, Kawazoe K, Matsuzaki S: Mechanisms of hepatic microcirculatory disturbances induced by acute ethanol administration in rats, with special reference to alterations of sinusoidal endothelial fenestrae. Alcohol Clin Exp Res 1999, 23(4 Suppl):39S-46S.

9. Wisse E, Jacobs F, Topal B, Frederik P, De Geest B: The size of endothelial fenestrae in human liver sinusoids: implications for hepatocyte-directed gene transfer. Gene Ther 2008, I5(17): I 193-1199.

10. Snoeys J, Lievens J, Wisse E, Jacobs F, Duimel H, Collen D, Frederik $P$, De Geest B: Species differences in transgene DNA uptake in hepatocytes after adenoviral transfer correlate with the size of endothelial fenestrae. Gene Ther 2007, 14(7):604-612.

II. Wisse E, De Zanger RB, Charels K, Smissen P Van Der, McCuskey RS: The liver sieve: considerations concerning the structure and function of endothelial fenestrae, the sinusoidal wall and the space of Disse. Hepatology I985, 5(4):683-692.

12. Oshita M, Takei $Y$, Kawano S, Yoshihara H, Hijioka T, Fukui $H$, Goto M, Masuda E, Nishimura Y, Fusamoto $H$, et al:: Roles of endothelin$I$ and nitric oxide in the mechanism for ethanol-induced vasoconstriction in rat liver. The Journal of clinical investigation I993, 9 I(4): | 337-| 342.

13. Yokomori H, Oda M, Ogi M, Yoshimura K, Nomura M, Fujimaki K, Kamegaya $\mathrm{Y}$, Tsukada N, Ishii H: Endothelin-I suppresses plasma membrane Ca++-ATPase, concomitant with contraction of hepatic sinusoidal endothelial fenestrae. The American journal of pathology 2003, I62(2):557-566.

14. Braet F, Wisse E: Structural and functional aspects of liver sinusoidal endothelial cell fenestrae: a review. Comp Hepatol 2002, I(I): I.

15. Deng XS, Deitrich RA: Ethanol metabolism and effects: nitric oxide and its interaction. Curr Clin Pharmacol 2007, 2(2): I $45-153$.

16. Nakano M, Kikuyama M, Hasegawa T, Ito T, Sakurai K, Hiraishi K, Hashimura E, Adachi M: The first observation of O2-generation at real time in vivo from non-Kupffer sinusoidal cells in perfused rat liver during acute ethanol intoxication. FEBS Lett 1995, 372(2-3): 140-143.

17. Yokoyama H, Fukuda M, Okamura Y, Mizukami T, Ohgo H, Kamegaya $\mathrm{Y}$, Kato $\mathrm{S}$, Ishii $\mathrm{H}$ : Superoxide anion release into the hepatic sinusoid after an acute ethanol challenge and its attenuation by Kupffer cell depletion. Alcohol Clin Exp Res 1999, 23(4 Suppl):7IS-75S.

18. Wisse E: An electron microscopic study of the fenestrated endothelial lining of rat liver sinusoids. J Ultrastruct Res 1970, 3I(I): I25-I50.

19. Wisse E: An ultrastructural characterization of the endothelial cell in the rat liver sinusoid under normal and various experimental conditions, as a contribution to the distinction between endothelial and Kupffer cells. J Ultrastruct Res 1972, 38(5):528-562.

20. Lievens J, Snoeys J, Vekemans K, Van Linthout S, de Zanger R, Collen $D$, Wisse $E$, De Geest $B$ : The size of sinusoidal fenestrae is a critical determinant of hepatocyte transduction after adenoviral gene transfer. Gene Ther 2004, I I(20): I523-I53I.
Publish with Bio Med Central and every scientist can read your work free of charge

"BioMed Central will be the most significant development for disseminating the results of biomedical research in our lifetime. "

Sir Paul Nurse, Cancer Research UK

Your research papers will be:

- available free of charge to the entire biomedical community

- peer reviewed and published immediately upon acceptance

- cited in PubMed and archived on PubMed Central

- yours - you keep the copyright

Submit your manuscript here:

http://www.biomedcentral.com/info/publishing_adv.asp
BioMedcentral 